\title{
Allogenic Stimulation in Early Pregnancy Improves Pre- and Postnatal Ontogenesis in BALB/cLac Mice
}

\author{
Ludmila GERLINSKAYA ${ }^{1)}$, Mikhail MOSHKIN ${ }^{1,2)}$ and Vadim EVSIKOV1) \\ ${ }^{1)}$ Institute of Systematics and Ecology of Animals, Siberian Branch of Russian Academy of \\ Sciences, 630091, Novosibirsk, Frunze str. 11, Russia, ${ }^{2)}$ Center of Northeast Asian Studies, \\ Tohoku University, Kawauchi, Aoba-ku, Sendai 980-8576, Japan
}

\begin{abstract}
The influence of allogenic stimulation on pregnancy and the development of progeny was studied in BALB/cLac female mice that were injected with C57BL/6J male (allogenic) red blood cells $(\mathrm{AB})$ on the second day after intrastrain mating. On the $4^{\text {th }}$ day of pregnancy AB-treated females had higher levels of plasma progesterone than syngenic blood (SB) treated females and controls (salinetreated). Administration of allogenic erythrocytes also stimulated embryo development and improved maternal behaviour. On the day of birth the incidence of new-born rejection was much lower in AB-treated mice than in SB-treated mice A battery of physiological and behavioural tests were used to assess the adaptive features of BALB/CLac males born to females injected with $\mathrm{AB}, \mathrm{SB}$ or saline. These offspring groups did not differ in parameters of maximum aerobic performance, cold resistance or humoral immune response. At the same time, offspring of antigenically challenged mothers had less adrenocortical and behavioural responses to emotional stressors than offspring of SB and saline treated females. $\mathrm{AB}$ males also had higher mating success than other male groups.

Key words: Allogenic stimulation, Plasma progesterone, Viability of progeny.
\end{abstract}

(J. Reprod. Dev. 46: 387-396, 2000)

M edawar's question [1] - "...how does the pregnant mother contrive to nourish within herself, for many weeks or months, a foetus that is an antigenically foreign body?"- prompted intensive studies on the foetal allograft paradox. These studies demonstrated multiple mechanisms of maternal immune tolerance versus the conceptus including: the anatomical position of the foetus; absence or lack of expression of class I and II major histocompatibility complex (MHC) in trophoblast tissue and in particular polymorphic antigens; the activity of blocking antibodies; and the foetalplacental production of immunosuppressive hormones and substances such as progesterone or HLA-G (nonclassical human MHC gene) protein

Accepted for publication: August 29, 2000

Correspondence: M. P. Moshkin
[2-7]. Moreover, in many cases this dissimilarity is more beneficial for than deleterious to embryo development $[8,9]$. For example, some medical surveys of recurrent spontaneous abortion and recurrent miscarriage have shown that the probability of these events was higher in cases where couples had matched HLA genes [2, 10-12]. By means of intra- and interstrain transfers of mice blastocysts, Evsikov et al. [13-15] showed that antigenic dissimilarity increases the viability and growth rates of embryos, but despite intensive studies the mechanisms responsible for both the survival of the foetal allograft and, in particular, the promotion of an MHC incompatible embryo are still unclear.

It was found recently that antigenic dissimilarity of mother and foetus influences the concentration of plasma progesterone which plays a key role in 
successful pregnancy. The increase in progesterone in circulation and especially at implantation sites is related to: (i) constraint of the immune attack on foetal allografts [16-18]; (ii) regulation of the trophic maintenance of embryo development [1921]; (iii) and establishing maternal behaviour [2224]. Both intra- and interstrain mating and embryo transplantations were used as models of homo- and heterotopic pregnancy in MHC differing mice BALB/cLac $\left(\mathrm{H}-2^{\mathrm{d}}\right)$ and C57Bl/6J $\left(\mathrm{H}-2^{\mathrm{b}}\right)[15,25]$. On the fourth day of heterotopic pregnancy, females of both strains had higher plasma progesterone than in homotopic pregnancy. Tissues of hybrid embryos also had higher levels of progesterone than pure-bred embryos.

Interstrain transplantation of early embryos allows the study of ontogenetic effects of mother and foetus dissimilarity on pure-bred offspring [26]. In this way, one can establish a strict demarcation between the effects of epigenetic (determined by mother-foetus interrelations) and genetic factors on the development of adaptive features in the progeny. Increased in postnatal growth rate in heterotopic transplantees in comparison with homotopic ones was found in reciprocal transfers of early embryos of BALB/cLac and $\mathrm{C} 57 \mathrm{Bl} / 6 \mathrm{~J}$ mice [15]. Adrenocortical responses to stress, as an important adaptive property [27-29] were also altered under the influence of heterotransplantation [Gerlinskaya, Evsikov, submitted for publication]. Heterotopic transferred progeny showed a minimal rise in plasma glucocorticoids in response to 15 -min pair-match testing or to 30-min crowding in comparison with other progeny, including pure-bred male mice BALB/cLac and C57Bl/6j, homotransplantees, and reciprocal hybrids.

The differences in progesterone concentrations in plasma and tissue partly explain the beneficial effects of mother-foetus dissimilarity, but it also raises new questions about the mechanism of MHC-dependent regulation of progesterone secretion. In particular, is short-term antigenic challenge enough for the endocrine and developmental effects seen in heterotopic pregnancy or do these effects need permanent interactions with the maternal immune system for semi-allogeneic (or allogeneic) foetuses? To answer this question unitary antigenic challenge of the immune systems of pregnant female mice was used. On the second day after intrastrain mating,
BALB/cLac were injected with blood of C57Bl/6J male mice. Two control groups were injected with either blood of BALB/cLac or saline. The injection time was chosen subsequent to our findings on the different levels of progesterone in early homotopic and heterotopic pregnancies, and also according to reported onset of $\mathrm{H}-2$ expression in mice embryos [30-32]. The plasma progesterone levels, embryo growth rates, pre- and postnatal embryo losses, and adaptive features of offspring were studied.

\section{Materials and Methods}

\section{Animals and maintenance}

The mice strains used, BALB/cLac and C57BL/ $6 \mathrm{~J}$, were bred at the Microbiology Research Centre «Vector» in Novosibirsk. The mice were housed in plastic cages $(30 \times 20 \times 10 \mathrm{~cm})$ on a light:dark 14L:10D schedule (light on at 04 a.m.) at 20-22 C. Water and food were available $a d$ lib. Males were housed individually and females were housed 5 per cage. Experiments were started no earlier than 3 weeks after the mice were obtained. Two-three month old mice were used in breeding experiments.

\section{Pregnancy, antigenic challenge, and rearing of offspring}

Oestrus females were placed with males of the same strain overnight. In the morning the females were examined and the detection of a vaginal plug was considered to represent day 0 of pregnancy. Pregnant females were placed individually in cages. Antigenic stimulation of the female immune system had been done according to the method of Humber et al. [33]. Three experimental groups of pregnant females were injected i.p. (40-42 h after mating) with: $50 \mu$ heparinized allogenic blood $(\mathrm{AB})$ of $\mathrm{C} 57 \mathrm{Bl} / 6 \mathrm{~J}$ male mice (group AB-28 females), $50 \mu l$ heparinized syngenic blood (SB) of BALB / cLac male mice (group SB-33 females), and $50 \mu \mathrm{l}$ sterile saline (group C-36 females). Male blood samples were taken from the retro-orbital sinus just before injection.

Female blood samples were taken for plasma by puncture of the retro-orbital sinus on the $4^{\text {th }}$ day of pregnancy. After centrifugation (3000 rpm, 15 min), the blood plasma was frozen $(-20 \mathrm{C})$ until later when the determinations were done for the progesterone concentration. On the $16^{\text {th }}$ day of 
pregnancy, nearly $1 / 3$ of the females were decapitated. The number of yellow cells and live embryos, and embryo body mass were assessed. Other females were kept until 4 weeks after delivery. Litter size was counted on the day of birth and after weaning. The offspring were then randomly distributed into unisex groups of 5 and housed in groups until 7-9 weeks of age. At this age, the males were separated and housed individually for 10-14 days before physiological and behavioural studies. Four behavioural tests were performed on 20-25 males from each experimental group at 5-7 day intervals in a standard sequence: open field test, pair-match test; encountering 3 males; and sexual behaviour. Humoral immune responses and maximal aerobic performance were studied in 10 males from each experimental group. All behavioural tests were performed between 02:00 and 06:00 p.m.

\section{Open field test (OFT)}

Tested males were placed in the centre of the arena (diameter $1 \mathrm{~m}$ ) illuminated by a 200 watt bulb. The latent time of movement, locomotion (number of crossed squares), vertical activity (rearing), grooming, and defecation (boluses) were registered over $3 \mathrm{~min}$. Immediately after the OFT, the rectal temperature was taken by means of a copper-constantan thermocouple with an accuracy of within $0.1 \mathrm{C}$.

\section{Basal level of rectal temperature and plasma corticosterone and testosterone}

Two days after the OFT basal level of rectal temperature and plasma steroids were assessed. The temperature was taken before puncturing the retro-orbital sinus. The time taken to collect blood did not exceed $2 \mathrm{~min}$. Thus the stressful effect of handling was avoided because the rise in blood glucocorticoids starts only $3-5 \mathrm{~min}$ after the onset of stress [34, 35].

\section{Social behaviour}

Aggressiveness and social competency of male mice were studied in the pair-match test and encounter of 3 males in a neutral area. The males were identified by shearing small areas of back fur to allow individuals to be distinguished easily. Mouse cages with clean saw dust were used in 15 min pair-match tests. Pairs were selected from mice within the same experimental group and with similar body weight. Blood sampling (from the retro-orbital sinus) was done immediately after testing. In the second test, one male from each experimental group was placed with others in a neutral arena ( $0.5 \mathrm{~m}$ diameter, three males per trial) with clean sawdust. The following types of behavioural acts for each individual were recorded in both tests:

- aggressive lunges were counted when a vigorous lunge towards to another was not accompanied by biting and wrestling;

- tail-rattles;

- fights were scored as the number of fights in which parties participated;

- defensive uprights;

- vocalisation;

Each act was scored as it occurred. Two scorers observed all trials. Ten preliminary pair-match tests indicated a high inter-observer correlation. The coefficient of correlation varied from $\mathrm{r}=0.831$ for vocalisation to $\mathrm{r}=0.924$ for aggressive lunges.

\section{Sexual behaviour}

Female offspring of non-treated mothers (7-9 weeks of age) were used as standard partners in the study of sexual behaviour. Oestrus females were introduced to individually housed males for 30 min. The number of mounts and intromissions were registered during this time. The males were then removed for blood sampling. After sampling the males were returned to their own cages and two females were also introduced. The next morning (09-11 a.m.) the females were inspected for a vaginal plug. Pregnant females were placed individually in cages, and the others were returned to the female cages.

\section{Humoral immune response}

Ten males from each group were injected intraperitoneally with $0.5 \mathrm{ml}$ sheep red blood cell (SRBC) suspension containing $4 \times 10^{8} \mathrm{SRBC} / \mathrm{ml}$ (experimental group). Injections were administered between 10 a.m. and 11 a.m. Five days after immunisation, the mice were killed under chloroform narcosis. The number of splenic plaque-forming cells (PFC) was estimated with the Cunningham technique [36].

\section{Maximal aerobic performance}

Short-term cold exposure in a helium-oxygen (Helox) atmosphere was used as stimulus for 
maximal oxygen consumption [37,38]. Males were placed in the chamber, regulated at $7 \mathrm{C}$, and aerated for $3 \mathrm{~min}$ by a circuit pump with a heliumoxygen mixture (80:20) from a gas tank. The total volume of this mixture was at least six times greater than the chamber volume. Then the Helox supply was stopped and the gas mixture was circulated through the hermetically closed circuit consisting of a pump, the chamber containing the mouse and an alkali $(\mathrm{KOH})$ container. This circuit was linked to a water manometer. Oxygen consumption was immediately measured for $1 \mathrm{~min}$, and at 5-6, 10-11 and 15-16 min after the Helox supply was shut off. Between measurements the air mixture was enriched with a volume of pure oxygen equal to that consumed by the animal. The maximum of the four values was taken as maximal oxygen consumption (MOC). Preliminary experiments showed that the oxygen consumption of these rodents in Helox proportionally increased with decreasing ambient temperature up to 10-12 C and then reached a plateau [39]. Therefore, the values for oxygen consumption obtained at $7 \mathrm{C}$ may be reliably treated as the individual maximal aerobic performance. The data on oxygen consumption were adjusted to standard conditions $(0 \mathrm{C}, 1,01 \times$ $\left.10^{6} \mathrm{~Pa}\right)$. Immediately after the last measurement the tested individual was removed from the chamber and its rectal temperature was recorded. Then blood samples (about $250 \mu \mathrm{l}$ ) were collect by

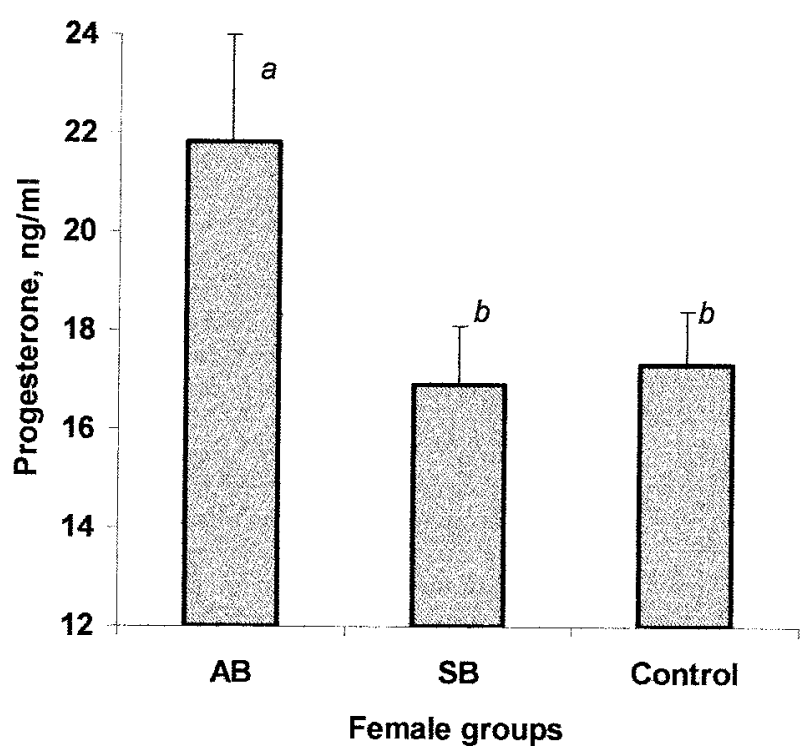

Fig. 1. Plasma progesterone on the $4^{\text {th }}$ day of pregnancy in female BALB/cLac mice treated with allogenic blood $(\mathrm{AB})$, syngenic blood (SB), and saline (Control). Here and in Figs. 2 and 3, each bar represents the mean \pm SE. Different superscripts indicate that means for experimental groups are significantly different (LSDtest, $\mathrm{P}<0.05)$.

Table 1. Ovulation rate, number of embryos, embryo losses and body mass of embryos in females in different experimental groups

\begin{tabular}{|c|c|c|c|}
\hline \multirow[t]{2}{*}{ Parameter } & \multicolumn{3}{|c|}{ Group of females } \\
\hline & $\mathrm{AB}$ & SB & Control \\
\hline Yellow cells & $7.55 \pm 0.91(10)$ & $6.61 \pm 0.42(13)$ & $8.08 \pm 0.67(13)$ \\
\hline $16^{\text {th }}$ days' embryo No. & $5.40 \pm 0.63(10)$ & $4.15 \pm 0.73(13)$ & $5.92 \pm 0.68(13)$ \\
\hline$\%$ of embryo losses & $34.9 \pm 5.2$ & $37.2 \pm 5.2$ & $26.7 \pm 4.3$ \\
\hline Embryo body mass, mg & $557 \pm 10(54)^{\mathrm{a}}$ & $519 \pm 8(54)^{\mathrm{b}}$ & $498 \pm 7(77)^{\mathrm{b}}$ \\
\hline
\end{tabular}

Table 2. Rejection of new-borns, pups per female and size of fostered litters in females in the different experimental groups

\begin{tabular}{llll}
\hline Parameter & \multicolumn{3}{c}{ Group of females } \\
\cline { 2 - 4 } & $\mathrm{AB}$ & $\mathrm{SB}$ & Control \\
\hline Rejected/Fostered litters & $0 / 18$ & $6 / 20$ & $5 / 23$ \\
\% rejection & $0 \pm 0$ & $30.0 \pm 10.2^{* *}$ & $21.7 \pm 8.6^{*}$ \\
Weaned pups per female & 5.44 & $3.85^{\#}$ & $3.78^{\#}$ \\
Size of fostered litters & $5.44 \pm 0.41$ & $5.50 \pm 0.44$ & $4.83 \pm 0.44$ \\
\hline * $-\mathrm{P}<0.05 ; * *-\mathrm{P}<0.01$ in comparison with group AB (Student's $t$-test). \\
\# - $\mathrm{P}<0.05$ in comparison with group AB ( Mann-Whitney test).
\end{tabular}


Table 3. Temperature and behavioural responses to novel environment (OFT) of offspring from different experimental groups

\begin{tabular}{lccc}
\hline \multirow{2}{*}{ Parameter } & \multicolumn{3}{c}{ Group of offspring } \\
\cline { 2 - 4 } & $\mathrm{AB}$ & $\mathrm{SB}$ & Control \\
\hline Latent time, sec & $8.83 \pm 2.07(25)$ & $6.20 \pm 0.61(24)$ & $6.68 \pm 0.81(25)$ \\
Defecation, boluses & $3.28 \pm 0.37(25)$ & $3.79 \pm 0.45(24)$ & $4.68 \pm 0.40(25)^{\#}$ \\
Locomotion, squares & $55.6 \pm 5.5(25)$ & $54.1 \pm 5.0(24)$ & $59.0 \pm 3.1(25)$ \\
Vertical activity, rearing & $5.88 \pm 1.22(25)$ & $7.41 \pm 0.85(24)$ & $6.68 \pm 0.19(25)$ \\
Grooming, acts & $0.60 \pm 0.18(25)$ & $0.58 \pm 0.20(24)$ & $0.84 \pm 0.19(25)$ \\
Rectal temperature, C & $37.6 \pm 0.12(25)^{\mathrm{b}}$ & $38.0 \pm 0.1(24)^{\mathrm{a}}$ & $37.9 \pm 0.1(25)^{\mathrm{b}}$ \\
\hline
\end{tabular}

$\#-\mathrm{P}<0.05$ in comparison with group $\mathrm{AB}$ ( Mann-Whitney test).

$\mathrm{a}, \mathrm{b}$ Values with different superscripts within a line differ significantly (at least $\mathrm{P}<0.05$; LSD test).

Table 4. Offensive and defensive behaviour of dominants and subordinates during a 15 min encounter of 3 males from different experimental groups

\begin{tabular}{lccc}
\hline Parameter & Dominants (17) & Subordinates (34) & Mann-Whitney test \\
\hline Aggressive lunge & $4.18 \pm 1.40$ & $0.44 \pm 0.11$ & $\mathrm{P}<0.002$ \\
Tail rattle & $4.94 \pm 1.02$ & $1.21 \pm 0.32$ & $\mathrm{P}<0.001$ \\
Defensive upright & 0 & $4.53 \pm 0.92$ & $\mathrm{P}<0.001$ \\
Vocalization & 0 & $1.57 \pm 0.43$ & $\mathrm{P}=0.05$ \\
\hline
\end{tabular}

Table 5. Sexual behavior and mating success (\% females with vaginal plug) of offspring from different experimental groups

\begin{tabular}{lccc}
\hline \multirow{2}{*}{ Parameter } & \multicolumn{3}{c}{ Offspring group } \\
\cline { 2 - 4 } & $\mathrm{AB}$ & $\mathrm{SB}$ & Control \\
\hline Mount & $3.91 \pm 1.20(23)$ & $1.24 \pm 0.51(21)^{\#}$ & $1.63 \pm 2.21(22)$ \\
Intromission & $1.17 \pm 0.51(23)$ & $0.09 \pm 0.06(21)^{\#}$ & $0.14 \pm 0.10(22)$ \\
$\%$ females with plug & $21.7 \pm 4.9(69)$ & $9.5 \pm 3.7(63)^{*}$ & $6.1 \pm 2.9(66)^{* *}$ \\
\hline
\end{tabular}

* $-\mathrm{P}<0.05$; ** $-\mathrm{P}<0.01$ in comparison with group $\mathrm{AB}$ (Student's $t$-test).

$\#-\mathrm{P}<0.05$ in comparison with group $\mathrm{AB}$ (Mann-Whitney test).

retro-orbital sinus puncture.

Plasma progesterone, corticosterone and testosterone

Plasma samples collected after testing were frozen before radio-immunoassay. Female plasma was assayed for progesterone concentrations with Sigma antibodies (anti-progesterone P-5289). The concentrations of corticosterone and testosterone were analysed in male samples. Sigma antibodies (anti-corticosterone C-8784 and anti-testosterone T4276) were used. An exclusion extraction analysis was performed according to the manufacturer's instructions. A uniform procedure of extraction preceded the radioimmunoassay of each hormone: $50 \mu \mathrm{l}$ plasma was extracted with $3 \mathrm{ml}$ ethyl ether; 2 $\mathrm{ml}$ extracts were removed, transferred to new tubes, vacuum dried at $37 \mathrm{C}$, and $300 \mu l$ phosphate buffer $(\mathrm{pH}=7.0)$ was added. Extraction yield assessed for every assay set with ${ }^{3} \mathrm{H}$ labelled steroids varied from 85 to $95 \%$. Sensitivities of the assays determined from $95 \%$ confidence limits of zero standards were $10 \mathrm{pg} /$ tube for progesterone, $15 \mathrm{pg} /$ tube for corticosterone and $5 \mathrm{pg} /$ tube for testosterone. To determine parallelism, a fivepoint, two-fold dilution series of plasma samples in phosphate buffer was constructed and compared with standard curves for these steroid hormones. There were no significant differences between the slopes of standard curves and slopes of lines generated by assayed samples.

\section{Statistical analysis}

One-way analysis of variance (ANOVA) was used to determine differences between groups with subsequent comparison of means by the LSD-test. Significance of differences between 2 groups was 
Table 6. Humoral immune response to SRBC, maximal oxygen consumption and rectal temperature before and after cold exposure in offspring from different experimental groups

\begin{tabular}{lccc}
\hline \multirow{2}{*}{ Parameter } & \multicolumn{3}{c}{ Group of offspring } \\
\cline { 2 - 4 } & $\mathrm{AB}$ & $\mathrm{SB}$ & Control \\
\hline PFG per mouse & $3286 \pm 367(20)$ & $4301 \pm 679(20)$ & $2813 \pm 461(20)$ \\
Maximal oxygen consumption, $\mathrm{ml} / \mathrm{g}$ h & $9.10 \pm 0.46(10)$ & $9.13 \pm 0.90(10)$ & $9.47 \pm 0.83(10)$ \\
Rectal temperature, C: & & & \\
under 20-22 C & $36.7 \pm 0.2(10)$ & $36.8 \pm 0.2(10)$ & $36.7 \pm 0.2(10)$ \\
after 15 min cold exposure & $25.9 \pm 0.6(10)$ & $26.2 \pm 0.6(10)$ & $26.4 \pm 0.7(10)$ \\
\hline
\end{tabular}

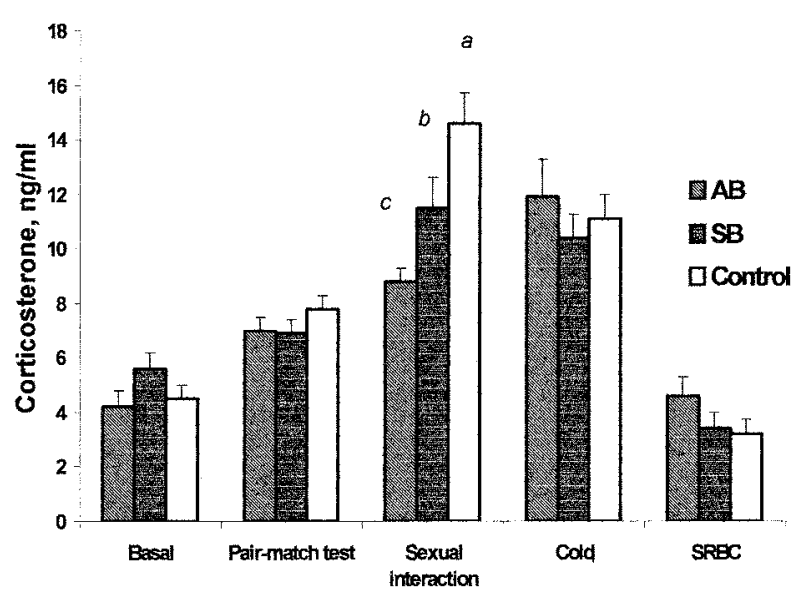

Fig. 2. Basal and stress-induced plasma corticosterone levels in offspring of females treated with allogenic blood $(\mathrm{AB})$, syngenic blood (SB), and saline (Control).

assessed by Student's $t$-test. Mann-Whitney test and $\chi^{2}$ were used for nonparametric comparisons.

\section{Results}

\section{Pregnant females}

Activation of the female immune system by injecting allogenic blood enhanced the rise in plasma progesterone (Fig. 1) that occurs in BALB/ cLac mice on the $4^{\text {th }}$ day of pregnancy [25]. There were no differences between experimental groups of pregnant females in the ovulation rate or the number of embryos (Table 1). The body mass of 16 day foetuses was higher in pregnant female injected with $\mathrm{AB}$ than in SB-treated females and controls. Rejection or eating of new-borns were found in $30.0 \%$ of SB females and $21.7 \%$ of controls. Females treated with $\mathrm{AB}$ reared all pups in all litters (Table 2). Due to differences in new-born rejection events the reproductive output, regarded

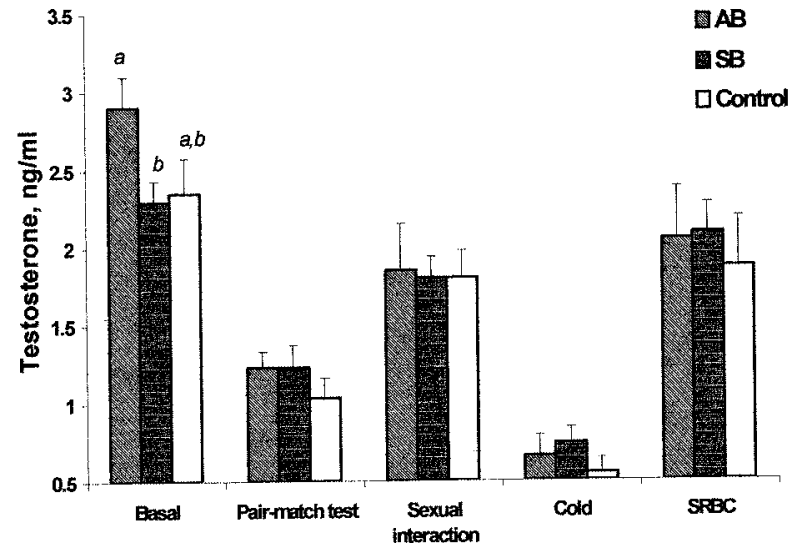

Fig. 3. Basal and stress-induced plasma testosterone levels in offspring of females treated with allogenic blood (AB), syngenic blood (SB), and saline (Control).

as the number of weaned pups per female, was higher in group $\mathrm{AB}$ than in group $\mathrm{SB}$ or controls, although the average litter sizes for fostered females were identical in all experimental groups.

\section{Adult offspring}

Increases in the defecation rate and body temperature are common vegetative manifestations of rodent emotional reactions to novel conditions [40]. Both characteristics were at minimal levels in the progeny of $\mathrm{AB}$ females (Table 3). We noted that basal levels of body temperature were similar in all experimental groups of offspring (Table 6).

All experimental offspring groups demonstrated the same lowest level of aggressiveness in pairmatch tests within groups. There were no fights between participants. Only in $8.3 \%$ of tests were aggressive lunges detected. The encounters of 3 males (one from each group) induced more aggressive acts, of which the number also did not differ between experimental groups. The highest 
ratio of offensive acts to defensive acts was used to recognise the dominant mouse in each trial (Table 4). In 3 tests we could not classify males according to hierarchical status, because all participants showed low aggressiveness. The ratio of dominants/ subordinates was maximal in group $\mathrm{AB}(9 / 8)$, intermediate in control group (5/12) and minimal in group SB $(3 / 14)$. The difference between groups $A B$ and SB was significant: $\chi^{2}=4.90$; $\mathrm{P}<0.05$.

During 30 min direct observation of sexual behaviour, we found that the progeny of antigenchallenged mothers (group AB) had more mounts than males in group SB. Vaginal plug inspections in females in contact for over 14-h with males showed higher mating success in group $A B$ than in SB and controls (Table 5).

The parameters reflecting resistance to infectious disease, such as humoral immune response to injection of SRBS, and resistance to physical stressors, such as aerobic performance and ability to maitain temperature homeostasis did not differ between male groups (Table 6).

Plasma corticosterone under basal conditions and immediately after stress stimuli showed identical levels in the experimental groups of males except in the mating test (Fig. 2). $30 \mathrm{~min}$ interactions with females induced maximal increases in plasma corticosterone in control males, but minimal in males in group AB. Males in group $S B$ had intermediate levels of plasma corticosterone. Maximal adrenocortical activation was found after the mating test and after extreme cold exposure. Basal levels of testosterone were significantly higher in males in group $A B$ than in males in group SB (Fig. 3). All stress stimuli induced decreases in testosterone levels that were identical in males of different experimental groups.

\section{Discussion}

The administration of $\mathrm{AB}$ type blood to pregnant BALB/cLac mice led to increased plasma progesterone in comparison with SB or saline treated females. Taken together, from this finding and those of our previous studies on plasma progesterone during homo- and heterotopic pregnancy in BALB/cLac mice [15, 25], we can conclude that each method of allogenic stimulation of female immune systems enhances progesterone secretion at implantation time. This activation of ovarian glands does not require permanent interactions between mother and semiallogenic or allogenic embryos. According to our findings, short-term unidirectional signals for the antigenic dissimilarity of foetuses seem to be sufficient for induction of the immuno-endocrine mechanism responsible for the additional increases in plasma progesterone during implantation. A key role in this mechanism might be the production of chorionic gonadotrophin by peripheral mononuclear cells that form mucosa associated lymphocyte tissues (MALT) in the fallopian tubes and endometrium [41, 42]. Local or general allogenic stimulation induces secretion of gonadotrophin by mononuclear cells [43] that can enhance the increase in plasma progesterone. Another mechanism of immune-dependent increase in progesterone secretion may be connected with the anti-luteolytic effects of some cytokines, such as Type I interferon-tau that prevents destruction of the corpus luteum by inhibiting the output of a luteolitic hormone, prostaglandin F2 alpha [44].

High levels of plasma progesterone in AB-treated females were associated with fast embryonic growth and with a zero incidence of pup rejection. The same relationships between plasma progesterone and embryonic development occurred in other cases of allogenic stimulation of pregnant BALB/cLac females: for example a transfer of $\mathrm{C} 57 \mathrm{Bl} / 6 \mathrm{~J}$ foetuses [15]. The key role of progesterone in the trophic maintenance of embryonic development is well known [19]. The different levels of plasma progesterone that were in between AB-treated and SB- and saline-treated females may be responsible for the differences in maternal behaviour, such as pup rejection. It was demonstrated by Wang et al. [22-24] that injection of pregnant mice with anti-progesterone antibody or with progesterone receptor antagonists impaired maternal care. It is remarkable that increased maternal rejection was found when preparations were administered on the $2^{\text {nd }}$ or $17^{\text {th }}$ day of pregnancy. Injection of anti-progesterone just after delivery (day 1 of lactation) had no effect. Progesterone levels at all stages of pregnancy are therefore important for the establishment of maternal behaviour.

The majority of studies dealing with the problem of mother and foetus immunogenetic dissimilarity 
are constrained to research on prenatal and early postnatal development. At the same time the physiology and behaviour of adult offspring also can be modified by allogenic maternal stimulation. According to our findings adrenocortical and temperature responses to some emotional stressors (mating test and OFT) were lower in males in group $\mathrm{AB}$ than in controls and group SB. Males in group $A B$ also had higher mating success and social competence than controls and group SB. Since both courtship efficiency and social dominance are androgen-dependent traits $[45,46]$, the difference between the experimental groups in plasma testosterone supports the finding of behavioural differences. Males in group AB had the highest level of plasma testosterone, and the greatest reproductive success, as well as the highest probability of dominating in social competition.

A trade-off between the manifestation of secondary sexual traits and immunocompetence was postulated in the "immunocompetence handicap" hypothesis [47]. Based on the dual effects of androgens in stimulating the development of sexual ornaments or intensity of sexual display [48] and suppression of immune function [17], the immunocompetence handicap hypothesis states that androgen-mediated development of morphological or behavioural secondary sexual characteristics comes at the expense of immunosuppression. In our studies there was no difference between experimental offspring groups in humoral immune response to a standard antigenic challenge, and the experimental groups had similar levels of maximal aerobic performance which is responsible for resistance to such physical stressor as extreme cold [37-39]. Despite the trade-off principle, the higher levels of testosterone and better development of androgendependent behavioural traits in offspring of allogenically stimulated females did not occur at the expense of resistance to infectious disease or low temperature.

In conclusion, this study has shown that the simulation of mother and foetus dissimilarity by injection of $A B$ induces widespread alterations, such as in the progesterone concentration in plasma, prenatal growth rate, sexual and social behaviour, and stress resistance in the progeny. Therefore, the evolutionary development by mammals of long-term intrauterine development not only affords embryo protection, but also act as a mechanism for creating phenotypic diversity, which underlies the dialogue between the genetically dissimilar mother and foetus.

\section{Acknowledgements}

We thank Dr. V. Mak and Dr. Yu. Novikov for assessment of the humoral immune response and maximal oxygen consumption and the anonymous experts for excellent correction of English. This work was supported by a grant from RFBS (Grant-99-04-49938).

\section{References}

1. Medawar PB. Some immunological and endocrinological problems raised by the evolution of viviparity in vertebrates. Symp Soc Exp Bio 1953; 7: 320-328.

2. Ober C. HLA and pregnancy: The paradox of the foetal allograft. Am J Hum Genet 1998; 62: 1-5.

3. Tafuri A, Alferink J, Moller P, Hammerling GJ, Arnold B. T cell awareness of paternal alloantigens during pregnancy. Science 1995; 270: 630-633.

4. Gonzalez NC, Chairez JA, Cueto SM. Immunology of the foetal-maternal relationship. Rev Alerg Mex 1996; 43: 18-22.

5. Spina V, Aleandri V, Pachiarotti A, Salvi M. Immune tolerance in pregnancy. Maternal-foetal interactions. Minerva Ginecol 1998; 50: 533-537.

6. Jiang SP, Vacchio MS. Multiple mechanisms of peripheral T cell tolerance to the foetal "allograft". J Immunol 1998; 160: 3086-3090.

7. Kaufman KA, Bowen JA, Tsai AF, Bluestone JA, Hunt JS, Ober C. The CTLA-4 gene is expressed in placental fibroblasts. Mol Hum Reprod 1999; 5: 84-87.

8. Billington WD. Influence of immunological dissimilarity of mother and foetus on size of placenta in mice. Nature 1964; 202: 317-318.

9. Fernandez N, Cooper J, Sprinks M, AbdElrahman M, Fiszer D, Kurpisz M, Dealtry G. A critical review of the role of the major histocompatibility complex in fertilization, preimplantation development and feto-maternal interactions. Hum Reprod Update 1999; 5: 234-248.

10. Komlos L, Zamir R, Joshua H, Halbrecht I. Common HLA antigens in couples with repeated 
abortions. Clin Immunol Immunopathol 1977; 7: 330335.

11. Schacter B, Muir A, Gyves M, Tasin M. HLA-A,B compatibility in parents of offspring with neuraltube defects or couples experiencing involuntary foetal wastage. Lancet 1979; 1: 796-799.

12. Gill TJ $3^{\text {rd }}$. Mechanisms of action of majorhistocompatibility-complex-linked genes affecting reproduction. Am J Reprod Immunol 1999; 41: 23-33.

13. Evsikov VI, Morozova LM. Role geneticphysiological interaction of mother-foetuses in establishing of mammalian viability and fertility Report I Embryonic development of mice in interstrain transference of blastocists. Genetics 1977; 5: 826-839 (In Russian).

14. Evsikov VI, Morozova LM. Role geneticphysiological interaction of mother-foetuses in establishing of mammalian viability and fertility. Report II. Weight embryos mice of strain BALB, CBA and DBA development from transference blastocists. Genetics 1978; 7: 1264-1271 (In Russian).

15. Evsikov VI, Gerlinskaya LA, Moshkin MP, Potapov MA, Osetrova TD. Genetic predetermined interaction mother-foetus and its influence on adaptive properties of offspring. Ontogenesis 1998; 29: 405-417 (In Russian).

16. Siiteri PK, Stites DP. Immunologic and endocrine interrelationships in pregnancy. Biol Reprod 1982; 26: $1-4$.

17. Grosman CJ. Regulation of the immune system by sex steroids. Endocrine Rev 1984; 5: 435-455.

18. Szekeres-Bartho J, Kinsky R, Kapovic M, Varga P, Chaouat G. Progesterone dependent immunomodulation. Reprod biol 1991; 93: 141-146.

19. Heap RB, Flint AP, Gadsby JE, Rice C. Hormones, the early embryo and the uterine environment. $J$ Reprod Fertil 1979; 55: 267-275.

20. Wilmut I, Sales DI, Ashworth CJ. Maternal and embryonic factors associated with prenatal loss in mammals. J Reprod Fertil 1986; 76: 851-864.

21. Uotinen N, Puustinen R, Pasanen S, Manninen T, Kivineva M, Syvala H, Tuohimaa P, Ylikomi T. Distribution of progesterone receptor in female mouse tissues. Gen Comp Endocrinol 1999; 115: 429441.

22. Crombie DL, Hayes JS, Heap RB, Wang MW. Antiprogesterone effects on maternal recognition and behaviour imprinted during first pregnancy in mice. J Endocrinol 1995; 145: 331-337.

23. Wang MW, Crombie DL, Mais DE, Hayes JS, Heap RB. Anti-progesterone antibody administration and the impairment of postpartum maternal care in mice. J Endocrinol 1995; 145: 363-369.

24. Wang MW, Crombie DL, Hayes JS, Heap RB. Aberrant maternal behavior in mice treated with a progesterone receptor antagonist during pregnancy. J Endocrinol 1995; 145: 371-377.
25. Evsikov VI, Gerlinskaya LA, Moshkin MP, Belogurova MP, Rogova OA. Progesterone concentration in early stage of homo- and heterogenous pregnancy of mice. Proc Acad Sci USSR 1991; 319: 494- 497 (In Russian).

26. Carlier M, Nosten-Bertrand M, Michard-Vanhee C. Separating genetic effects from maternal environmental effects. In: Goldowitz D, Wahlsten D and Wimer RE (eds.), Techniques for the Genetic Analysis of Brain and Behaviour. Paris: Elsevier Science Publishers BV; 1992: 111-126.

27. Ganem GA. A comparative study of different populations of Mus musculus domesticus: emotivity as an index of adaptation to commensalism. Comp Biochem Physiol 1991; 4: 531-536.

28. Moshkin M, Gerlinskaya L, Evsikov V. Variability of stress-reactivity in a natural population of water vole, Arvicola terrestris. Pol Ecol Stud 1994; 20: 409415.

29. Ramos A, Marmede P. Stress and emotionality: a multidimensional and genetic approaches. Neurisci Biobehav Rev 1997; 22: 33-57.

30. Krco CJ, Goldberg EM. Major histocompatibility antigens on preimplantation mouse embryos. Trans Proc 1977; 9; 1367-1370.

31. Warner CM, Brownell MS, Ewoldsen MA. Why are not embryos immunologically rejected by their mothers. Biol Reprod 1988; 38: 17-29.

32. Warner CM, Paschetto MG. Analysis of mRNA levels for the MHC class I-like molecules CD1 and FCRn in preimplantation mouse embryos. Am J Reprod Immunol 2000; 43: 234-239.

33. Humber DP, Mahouy G, Chinn S, Barnes RD. The influence of parity and maternal preimmunization on foetal survival in mice. J Reprod Fert 1974; 41: 193-196.

34. Kiohisa T, Kazuko I, Yasuro T. Parallel shift in circadian rhythms of adrenocortical activity and food intake in blinded and intake rats exposed to continuous illumination. Endocrinol 1977; 100: 10971107.

35. Kugler Y, Lange KW, Kalveram K. Th. Influence of bleeding order on plasma corticosterone concentration in the mouse. Exp Clin Endocrino 1988; 91: 241-243.

36. Cunningham AJ. A method of increased sensitivity for detecting single antibody-forming cells. Nature 1965; 207: 1106-1107.

37. Rosenmann M, Morrison P. Maximum oxygen consumption and heat loss facilitation in small homeotherms by $\mathrm{He}_{2} \mathrm{O}_{2}$. Am J Physiol 1974; 226: 490495.

38. Wang LCH. Modulation of maximum thermogenesis by feeding in the white rat. J Appl Physiol 1980; 49: 975-978.

39. Novikov E, Novikova M,Petrovski D, Moshkin M. Geographic and seasonal variations of metabolic 
activity in Siberian populations of mole vole (Ellobius talpinus). In: Zaim A (ed.), Biodiversity and Adaptation. Fifth International Conference "Rodens and Spatium". Rabat: Actes Editions; 1996: 77-88.

40. Markel AL, Galaktionov YK, Efimov VM. Factor analysis of rat behavior in an open field test. Neurosci Behav Physiol 1989; 19: 279-286.

41. Morris H, Edwards J, Tiltman A, Emms $\mathbf{M}$. Endometrial lymphoid tissue: An immuno histological study. J Clin Pathol 1985; 38: 644-652.

42. Morris H, Emms M, Visser T, Timme A. Lymphoid tissue of the normal fallopian tube: A form of mucosa-associated lymphoid tissue (MALT)? Int J Gynecol Pathol 1986; 5: 11-22.

43. Alexander $\mathbf{H}$, Zimmermann $G$, Lehmann $\mathbf{M}$, Pfeiffer R, Schone E, Leiblein S, Ziegert M. HCG secretion by peripheral mononuclear cells during pregnancy. Domestic Anim Endocr 1998; 15: 377-387.
44. Mathialagan N, Roberts RM. A role for cytokines in early pregnancy. Indian I Physiol Pharmacol 1994; 38: 153-162.

45. Naumenko EV, Osadchuk AV, Serova LI, Shishkina GT. Genetic and Physiological Mechanisms of Testicular Functions. 1983, Novosibirsk, Nauka (In Russian).

46. Moshkin MP, Evsikov VI, Pljusnin JuM, Gerlinskaya LA, Marchenko OV. Endocrine function of gonad and aggressiveness in male water vole at population decline. Ecology 1984: 4; 46-53 (In Russian).

47. Folstad I, Karter AJ. Parasites, bright males, and the immunocompetence handicap. Am Nat 1992; 139: 603-622.

48. Andersson M. Sexual Selection 1994 Princeton, New Jersey: Princeton Univ Press. 